\title{
La labor creadora de derecho del TJUE en la configuración de los despidos colectivos
}

\author{
The law creating work of the Court of Justice of the European union \\ in the configuration of collective dismissals
}

\author{
Dra. Ana Isabel PÉREZ CAMPOS \\ Universidad Rey Juan Carlos \\ Madrid
}

\begin{abstract}
Resumen: La protección jurídica del despido colectivo en la Unión Europea se articula sobre la premisa de la armonización de legislaciones, a través de la Directiva 98/59/CE de 20 de julio que establece la noción de despido colectivo y del procedimiento que ha de seguirse para despedir colectivamente y donde el papel del Tribunal de Justicia de la Unión, en la configuración de los perfiles del despido colectivo, está resultando esencial. Más allá del dato numérico de las sentencias, lo cierto es que se trata de resoluciones que, entre otros aspectos, han permitido detectar desajustes en la transposición de la Directiva al ordenamiento español y, por tanto, se hace necesario valorar una posible reforma legislativa.
\end{abstract}

La actual configuración jurídica del despido colectivo y la eficacia armonizadora está en entredicho hoy más que nunca, por la intensa labor interpretativa llevada a cabo por el TJUE, ante las diversas cuestiones prejudiciales que se han venido planteando por los tribunales nacionales.

\footnotetext{
Abstract: The legal protection of collective dismissal in the European Union is based on the premise of the harmonization of laws, through Directive 98/59/CE of July 20, which establishes the notion of collective dismissal and the procedure to be followed for dismiss collectively and where the role of the Court of Justice of the Union, in shaping the profiles of collective dismissal, is proving essential. Beyond the numerical data of the judgments, the truth is that these are resolutions that, among other aspects, have made it possible to detect imbalances in the transposition of the Directive into the Spanish legal system and, therefore, in the need to assess a possible legislative reform.
} 
The current legal configuration of collective dismissal and the harmonizing effectiveness is in question today more than ever, due to the intense interpretive work carried out by the CJEU, in the face of the various preliminary rulings that have been raised by the national courts.

Palabra clave: Tribunal de Justicia de la Unión Europea, despido colectivo, armonización, trabajador

Keywords: Court of Justice of the European Union, collective dismissal, harmonization, worker.

Sumario:

I. Introducción.

II. El impacto del Tribunal de Justicia de la Unión Europea en la configuración del despido colectivo.

III. La revisión de los elementos configuradores de la noción de despido.

3.1. A nivel causal.

3.1.1. Extinciones computables.

3.1.2. Extinciones no computables.

3.2. A nivel de umbrales de referencia.

3.2.1. Unidad de referencia espacial.

3.2.2. Unidad de referencia temporal.

IV. Un apunte sobre la delimitación conceptual del despido colectivo en el derecho comparado.

V. La eficacia armonizadora de la Directiva 98/59/CE.

VI. Bibliografía.

Recibido: octubre 2021.

Aceptado: diciembre 2021. 


\section{INTRODUCCIÓN}

La protección jurídica del despido colectivo en la Unión Europea se articula sobre la premisa de la armonización de legislaciones, a través de la Directiva 98/59/CE, de 20 de julio que establece la noción de despido colectivo y el procedimiento que ha de seguirse para despedir colectivamente y donde el papel del Tribunal de Justicia de la Unión Europea (TJUE) en la configuración de los perfiles del despido colectivo está resultando ser fundamental. Más allá del dato numérico de las sentencias, lo cierto es que se trata de resoluciones que abordan cuestiones del máximo interés y a la vista de últimos pronunciamientos judiciales, se trata de una cuestión que aún no puede considerarse cerrada.

La configuración del despido colectivo se basa en la confluencia de diversos elementos -causal y numérico-; éste último computado sobre los trabajadores despedidos en función de unas unidades de referencia temporal y espacial. A raíz de diferentes pronunciamientos del TJUE -muchos de ellos provenientes de España-, se han ido perfilando los elementos configuradores de la noción del despido colectivo y su adecuación a la Directiva 98/59/CE, y se han puesto de relieve diferencias o desajustes entre la norma comunitaria y la española.

La actual configuración jurídica del despido colectivo y la eficacia armonizadora está en entredicho hoy más que nunca, por la intensa labor interpretativa llevada a cabo por el TJUE, ante las diversas cuestiones prejudiciales que se han venido planteando por los tribunales nacionales.

Con este estudio se pretende realizar un análisis jurídico de las discordancias entre la norma europea y el ordenamiento español a la hora de regular la figura del despido colectivo, así como analizar la eficacia de la armonización comunitaria. Se trata de una cuestión que no va a estar exenta de dificultades.

\section{EL IMPACTO DEL TJUE EN LA CONFIGURACIÓN ACTUAL DEL CONCEPTO DE DESPIDO COLECTIVO}

En los últimos años, han aumentado considerablemente las cuestiones prejudiciales relacionadas con el despido colectivo y el impacto de la doctrina 
del Tribunal de Justicia de la Unión Europea ha provocado en el ordenamiento español, bien una reinterpretación o modulación de la jurisprudencia, o bien una modificación normativa por parte de los Estados miembros. España no es una excepción, incluso podría señalarse que el incremento de cuestiones prejudiciales es directamente proporcional con los desajustes detectados por el alto tribunal entre la normativa española y las Directivas comunitarias en materia laboral. Un ejemplo actual a destacar sería el relativo a la delimitación conceptual del despido colectivo y su adecuación con la Directiva 98/59/CE, de 20 de julio de 1998, que de forma intermitente, aunque prolongada en el tiempo, han sido resueltas por el TJUE, a través de un proceso de revisión marcado de luces y sombras y que ha provocado que se cuestione si resulta necesaria una revisión a nivel nacional.

En el marco normativo supranacional, la Directiva 98/59/CE delimita la noción de despido colectivo sobre la base de dos componentes esenciales:

- Un primer elemento cualitativo referido a los motivos del despido, considerando como tales a todos aquellos que se produzcan por "circunstancias no inherentes a la persona de los trabajadores afectados". La Directiva no establece la causalidad específica de este despido, sino que de forma genérica y abierta se refiere al despido sin concretar los motivos que justifican la decisión extintiva. Así, el hecho de que las extinciones se funden en causas distintas impedirá apreciar la existencia de un despido colectivo, aunque los trabajadores afectados sean más que aquellos de los que depende el elemento o requisito numérico ${ }^{1}$.

- Un segundo elemento es el cuantitativo-temporal que combina un número mínimo de despidos dentro de un marco temporal determinado de 30 o 90 días. En concreto, se establece que para un período de 30 días será despido colectivo "el que afecte al menos igual a 10 en los centros de trabajo que empleen habitualmente más de 20 y menos de 100 trabajadores, al menos el $10 \%$ del número de los trabajadores, en los centros de trabajo que empleen habitualmente como mínimo 100 y menos de 300 trabajadores, al menos igual a 30 en los centros de trabajo que empleen habitualmente 300 trabajadores, como mínimo". Y para un período de 90 días el despido será colectivo "cuando afecte al menos igual a 20, sea cual fuere el número de los trabajadores habitualmente empleados en los centros de trabajo".

Por tanto, serán despidos colectivos las extinciones sustentadas en causas ajenas o independientes de la conducta del trabajador y que, además, se integren en el elemento cuantitativo y temporal especificado en la normativa comunitaria.

${ }^{1}$ GÁRATE CASTRO, J., "Régimen jurídico del despido colectivo", en Revista, Dereito, Vol. 22, no extraordinario, (2013) 120. 
En el marco normativo español, el concepto de despido colectivo -art. 51 ETexige la concurrencia de una serie de requisitos: Un elemento causal constituido por la constatación de causas económicas, técnicas, organizativas o de producción. Un elemento cuantitativo, condicionado al volumen de plantilla de la empresa afectada:

- Diez trabajadores, en las empresas que ocupen menos de cien trabajadores.

- El diez por ciento del número de trabajadores de la empresa en aquellas que ocupen entre cien y trescientos trabajadores.

- Treinta trabajadores en las empresas que ocupen más de trescientos trabajadores.

Un elemento temporal o periodo observado, limitado a un período de noventa días. Igualmente, será despido colectivo, por asimilación ex lege, la extinción que afecte a la totalidad de la plantilla de la empresa, debiendo de concurrir dos requisitos: numérico -que el número de trabajadores afectados sea superior a cinco-, y causal -la extinción se produzca como consecuencia de la cesación total de su actividad empresarial- ${ }^{2}$.

El despido colectivo se define, además de por la causa, por el número de trabajadores afectados. En el caso de despido colectivo "total", derivado del cese total de la actividad empresarial por las causas ya señaladas, se precisa que los trabajadores afectados sean más de cinco (art. 51.1, párrafo cuarto, del ET), lo que significa que las empresas con cinco o menos trabajadores que cesen de modo definitivo en su actividad por causas económicas, técnicas, organizativas o de producción habrán de amparar su decisión extintiva en el art. 52.c) del ET y seguir los trámites que para el despido objetivo señalados en el art. 53 ET.

A pesar del planteamiento normativo que se acaba de describir y que aparentemente confirma la correcta transposición de la Directiva en el derecho laboral español, sin embargo, las frecuentes cuestiones prejudiciales planteadas por los jueces nacionales han descubierto desajustes en dicha transposición. En los últimos años, a raíz de los pronunciamientos del Tribunal de Justicia, se evidencia un desajuste entre las legislaciones nacionales y la Directiva comunitaria, y que es especialmente relevante en el caso del derecho español.

${ }^{2}$ GARCÍA PERROTE ESCARTÍN, I., "La aplicación por el Tribunal de Justicia de la Unión Europea de la Directiva sobre despidos colectivos y su repercusión en el derecho español", en Actualidad Jurídica Uría Menéndez, 49 (2018) 169-188. MIÑARRO YANINI, M., "La causa del despido colectivo en el Convenio n. ${ }^{\circ} 158$ de la OIT y en la Directiva 98/59/CE", en Actualidad laboral, 8 (2011) 5. 
Sin perjuicio de un análisis más detallado, a modo de visión panorámica, pueden destacarse diferencias apreciables en la noción de despido colectivo: en primer lugar, las relativas a la delimitación subjetiva, esto es, al alcance de las causas o motivos de despido, así como a la determinación de los sujetos y el tipo de extinciones que computan. En segundo lugar, también han sido relevantes los desajustes entre el derecho español y el comunitario en relación con la unidad de referencia para el cómputo de los despidos y la delimitación temporal cuantitativa de estos sobre el cómputo de trabajadores afectados. En tercer lugar, los criterios para determinar el número de trabajadores de la empresa y las extinciones que deben ser computadas a efectos de determinar un despido colectivo, son cuestiones que también han dado lugar a diversos pronunciamientos del TJUE. Todo ello sin olvidar que se han planteado otras dudas interpretativas, tales como si deben computar dentro del despido colectivo las extinciones de contratos de trabajo vinculados a una contrata, el despido de mujeres embarazadas, o incluso si una modificación sustancial puede computar a efectos de despido colectivo o si un cierre de un centro de trabajo puede asimilarse a un cierre de empresa ex art. 51.1 ET a los efectos de su calificación como despido colectivo.

\section{LA REVISIÓN DE LOS ELEMENTOS CONFIGURADORES DE LA NOCIÓN DE DESPIDO}

\subsection{A nivel causal}

La Directiva 98/59/CE no impone a los Estados miembros que el despido colectivo tenga que ser causal, sino que simplemente considera despido colectivo, a los efectos de la obligación de consulta e información, las extinciones decididas por la empresa por cualquier motivo no inherente a la persona de los trabajadores que superen determinados umbrales numéricos, en un periodo temporal de referencia.

Esta inconcreción produce, por una parte, el efecto de extender el ámbito de aplicación de la Directiva, pues permitirá incluir a todos los despidos que alcancen los umbrales numéricos fijados en la norma y que se produzcan por cualquier motivo que no sea inherente a la persona del trabajador ${ }^{3}$. Por otra parte, provoca también una considerable incertidumbre acerca de qué concretos supuestos extintivos pueden ser o no constitutivos de un despido colectivo.

A nivel nacional, el art. 51 del ET al referirse a los motivos que pueden configurar un despido colectivo alude a unas concretas causas -económicas,

\footnotetext{
${ }^{3}$ MIÑARRO YANINI, M., "La causa del despido colectivo en el Convenio n. ${ }^{\circ} 158$ de la OIT y en la Directiva 98/59/CE”..., o.c., p. 7.
} 
técnicas, organizativas y de producción- y, por tanto, no parece compatible con la Directiva limitar el concepto de despido colectivo sólo a los despidos por dichas causas ${ }^{4}$. El Gobierno español justificó la fórmula seguida por la norma de transposición nacional en que incluye una disposición, que califica de "comodín", según la cual, para el cómputo del número de extinciones de contratos, se tendrán en cuenta asimismo cualesquiera otras extinciones producidas por iniciativa del empresario en virtud de otros motivos no inherentes a la persona del trabajador afectado, distintos de la finalización de los contratos de trabajo celebrados por un periodo de tiempo limitado o para la realización de una tarea determinada (contratos de duración determinada), siempre que su número sea al menos de cinco.

Como ha señalado la doctrina científica bajo la interpretación literal de "despidos por motivos no inherentes a la persona del trabajador" de la normativa comunitaria frente a la relativa a "despidos por causas económicas, técnicas, organizativas o de producción" de la normativa española, late un nuevo desajuste que parte de la deficiente transposición de aquella cuando se traduce en la expresión española que resulta ser más restrictivo que el de la europea, en la medida en que deja fuera de su ámbito las extinciones asimiladas"5.

En consecuencia, las extinciones computables a efectos de despido colectivo han sido otro de los elementos objeto de debate judicial, donde se ha venido considerando que ante la indeterminación de la Directiva el concepto de "despido" debe ser objeto de una interpretación uniforme a la finalidad u objetivo procedimental de la mencionada Directiva, y no causal y que, en consecuencia, la regulación de las causas que se exigen para realizar un despido colectivo es una materia que es competencia de los Estados miembros. Por tanto, se podrían incluir en el citado concepto cualquier extinción del contrato de trabajo no pretendida por el trabajador y sin que tal concepto exija que las causas subyacentes correspondan a la voluntad del empresario ${ }^{6}$.

Tanto la jurisprudencia comunitaria como la española han venido pronunciándose sobre qué tipo de extinciones son computables a efectos de despido.

De conformidad con la STJUE de 10 de diciembre de 2009, Rodríguez Mayor asunto C- 323/08, en la que se planteaba la compatibilidad del artículo 49.1 g) ET

\footnotetext{
${ }^{4}$ GARCÍA-PERROTE ESCARTÍN, I., "La aplicación por el tribunal de justicia de la unión europea de la directiva sobre despidos colectivos y su repercusión en el derecho español", o.c., p. 176.

${ }^{5}$ DESDENTADO BONETE, A., La delimitación legal del despido colectivo. El despido colectivo de hecho, en VV.AA., Tratado de despido colectivo, Dir. Martín Godino Reyes, 2016, p. 30.

${ }^{6}$ STJUE de 12 de octubre de 2004, Comisión/Portugal, asunto C-55/02. STJUE de 7 de septiembre de 2006 Agorastoudis y otros, asuntos acumulados C-187/05 a C-190/05.
} 
con la Directiva 98/59/CE, el Tribunal consideró que no era contrario a la Directiva la no consideración de despido colectivo de la extinción de los contratos de trabajo de varios empleados como consecuencia de la muerte del empresario persona física.

Más recientemente, en la STJUE de 13 de mayo de 2015, Rabal Cañas, asunto C- 392/13 en una de las cuestiones prejudiciales también se planteaba si el concepto de "despido colectivo", establecido en el art. 1.1.a) de la Directiva se opone o es contrario a que la norma de transposición, el art. 51.1 ET, restrinja el ámbito del despido solamente a las extinciones fundada por causas económicas, técnicas, organizativas o de producción, cuando la Directiva parece ofrecer una noción de despidos colectivos más amplia que incluiría como despidos colectivos aquellos efectuados por un empresario por uno o varios motivos no inherentes a la persona de los trabajadores. Sin embargo, el Tribunal de Justicia elude responder a esta primera cuestión prejudicial, tras llegar a la conclusión de que no resulta de aplicación la Directiva, pues el centro de trabajo en el que se habían producido las extinciones no tenía más de 20 trabajadores. Un silencio de lo más elocuente, como ha calificado la doctrina científica ${ }^{7}$.

\subsubsection{Extinciones computables}

A partir de esta premisa, la jurisprudencia y la doctrina judicial española también han ido dotando de contenido a la expresión genérica utilizada por el legislador comunitario. Así pues, debe entenderse "por motivos inherentes a la persona del trabajador", en principio, aquellos que proceden de la propia y directa voluntad del trabajador, pero también los que, aun no debiéndose a su voluntad, derivan de causas vinculadas con su persona.

También han sido evidentes las diferencias entre la regulación comunitaria y española en relación con el cómputo de otras extinciones del contrato de trabajo a iniciativa empresarial y su asimilación a despidos y, por tanto, a su inclusión en los umbrales de un despido colectivo y más específicamente en la asimilación referida en el segundo párrafo del apartado a) del artículo 1, apartado 1 de la Directiva 98/59/CE que indica que "a efectos del cálculo del número de despidos previsto en la letra a) se asimilarán a los despidos colectivos las extinciones del contrato de trabajo producidas por iniciativa de empresario en base a uno o varios motivos no inherentes a la persona de los trabajadores, siempre y cuando los despidos sean al menos 5". Por su parte, el artículo 51, apartado 1, del Estatuto

${ }^{7}$ CASTRO ARGÜELLES, M ${ }^{\mathrm{a}}$ A., "Los conceptos de «centro de trabajo» y «despido colectivo» en el «Derecho de la Unión», a propósito de la Directiva 98/59/CE”, en La Ley Unión Europea, 29 (2015) 9. 
de los Trabajadores establece que para el cómputo del número de extinciones de contratos a los efectos de los umbrales del despido colectivo han de tenerse en cuenta cualesquiera otras extinciones producidas en el período de referencia por iniciativa del empresario en virtud de otros motivos no inherentes a la persona del trabajador distintos de los previstos en el artículo 49.1.c), siempre que el número de las mismas sea, al menos, de cinco. En consecuencia, aquí ya no se cuestionan los motivos que justifican la decisión extintiva ${ }^{8}$, prevaleciendo el hecho de que se hayan producido en virtud de una decisión empresarial, lo que supone que prevalece el número de trabajadores afectados frente a la causa.

La duda interpretativa que se ha planteado en cuanto a la exigencia mínima legal de «cinco extinciones», es la relativa a si se refiere a «cinco extinciones contractuales distintas de los despidos objetivos por causas económicas, técnicas, organizativas o de producción», o si, por el contrario, se refiere a «cinco despidos objetivos por causas económicas, técnicas, organizativas o de producción». La jurisprudencia española se mostró partidaria de incluir otras extinciones contractuales distintas de los despidos por causas económicas, técnicas, organizativas o de producción ${ }^{9}$. Por el contrario, la jurisprudencia comunitaria se decantó a favor de la interpretación relativa a que el número de cinco alude solamente a los despidos por causas económicas, técnicas, organizativas o de producción y no a otras extinciones contractuales asimiladas ${ }^{10}$.

La condición de que sean al menos cinco los despidos para que puedan computarse y asimilarse otras formas de extinción contractual es analizada en la STJUE de 11 de noviembre de 2015, Pujante Rivera, asunto C-422/14, donde el tribunal considera que la Directiva se refiere, única y exclusivamente, a despidos entendidos como extinciones llevadas a cabo bajo la forma de un despido. Según el considerando 8 de la Directiva, y con el fin de calcular el número de despidos previsto en la definición de su modalidad colectiva, "conviene asimilar a los despidos otras formas de extinción del contrato de trabajo efectuadas por iniciativa del empresario, siempre y cuando los 'despidos' sean como mínimo cinco"' .

Se ha cuestionado también si resultarían incluidos en el cómputo los despidos por fuerza mayor y las extinciones por muerte, jubilación e incapacidad de la

\footnotetext{
${ }^{8}$ MONEREO PÉREZ, J.L., "El despido colectivo en la jurisprudencia de Tribunal de Justicia de la Unión Europea y su incidencia en el Derecho interno", en Temas Laborales, 130 (2015) 320.

${ }^{9}$ STS de 23 de abril de 2012, (Rec. 2724/2011); STS 8 de julio de 2012, (Rec. 2341/2011) y STS de 25 de noviembre de 2013, (Rec. 52/2013).

${ }^{10}$ STJUE de 11 de noviembre de 2015, Pujante Rivera, asunto C-422/14; STJUE de 21 de septiembre de 2017, Socha y otros, asunto C-149/16 y STJUE de 21 de septiembre de 2017, Ciupa y otros, asunto C-429/16.

${ }^{11}$ STJUE 11 noviembre 2015, Pujante Rivera, asunto C-422/14, apartado 45.
} 
persona física titular de la empresa y por extinción de la personalidad jurídica de la empresa. En este sentido, el Tribunal de Justicia incluye en el cómputo previsto por la Directiva los despidos por fuerza mayor y el cese de la actividad de la empresa a raíz del fallecimiento de la persona titular de la empresa $^{12}$, así como las extinción como consecuencia de una modificación sustancial no inherente al trabajador previstas en los artículos 40,41 y $50 \mathrm{ET}^{13}$. El TJUE considera que a los efectos de la Directiva se incluye cualquier forma de extinción del contrato de trabajo que sea por causa ajena al trabajador; parece entenderse que cualquier resolución del contrato basada en los artículos 40, 41 y 50 ET debería asimilarse a un despido y computar, por tanto, a los efectos de su determinación ${ }^{14}$.

A partir de aquí se constata la divergencia entre lo señalado por el TJUE y los tribunales españoles que han venido excluyendo del cómputo de extinciones, a los efectos de los umbrales del despido colectivo, las extinciones contractuales derivadas de modificaciones sustanciales y movilidad geográfica del trabajador, ya que, a pesar de que en el origen de la extinción exista una decisión empresarial, es la facultad resolutoria del vínculo contractual que ejercita el trabajador la que se constituye en requisito indispensable para que tal resolución opere ${ }^{15}$.

\subsubsection{Extinciones no computables}

La concreción de las causas a efectos de cómputo de despido colectivo también ha provocado que se excluyan las extinciones de contratos de duración determinada que se extingan por llegada del término y no se contabilicen como despidos colectivos, porque los contratos de duración determinada "no se extinguen a iniciativa del empresario, sino en virtud de las cláusulas que contienen

\footnotetext{
${ }^{12}$ STJUE de 12 de octubre de 2004, Comisión/Portugal, asunto C-55/02. Sobre el cómputo de la extinción a efectos de despido colectivo, véase, SALA FRANCO, T., "Balance jurisprudencial acerca del concepto legal de despido colectivo y del cómputo de las extinciones contractuales producidas en un periodo de 90 días", Revista de Trabajo y Seguridad Social. CEF, 455 (2021), 163.

${ }^{13}$ El concepto de despido del art. 1.1 de la Directiva 98/59 es «un concepto de Derecho de la Unión que no puede ser definido mediante remisión a las legislaciones de los Estados miembros»y, en principio, incluye «cualquier extinción del contrato no deseada por el trabajador y, en consecuencia, sin su consentimiento» (STJUE Pujante Rivera -apartado 48- y las sentencias allí citadas).

${ }^{14}$ STJUE de 11 de noviembre de 2015, Pujante Rivera, asunto C-422/14. GÓMEZ ABELLEIRA, F.J. y DÍAZ ZAFORAS, D., "La construcción judicial del concepto de despido colectivo por el tribunal de justicia de la unión europea", Revista Española de Derecho Europeo, 57 (2016) 53.

${ }^{15}$ SSTSJ Madrid 20 de enero de 2014 (AS 2014, 290) y País Vasco de 14 de abril de 2015 (JUR 2015, 169069), entre otras.
} 
o de la normativa aplicable, cuando llegan a término o cuando se realiza la tarea para la que fueron celebrados"16. Ahora bien, como se ha matizado cuestión distinta es que los trabajadores con contratos de duración determinada no se computen a efectos de determinar el número de los empleados habitualmente en el centro de trabajo. Esto último no se deduce de ningún pasaje de la Directiva ${ }^{17}$.

En los mismos términos, tampoco se consideran extinciones computables a efectos de despido colectivo las producidas por dimisión o abandono del trabajador, ni las derivadas de su jubilación, incapacidad o muerte. Tampoco las motivadas por mutuo acuerdo, siempre que el acuerdo extintivo no se produzca a instancia del empresario, sino por la voluntad concorde de las $\operatorname{dos}^{18}$, o incluso deben excluirse las extinciones en período de prueba, en la medida en que la terminación del contrato deriva de una valoración del empresario sobre la capacidad del trabajador ${ }^{19}$.

Otra cuestión controvertida y resuelta por la jurisprudencia es la relativa a qué debe entenderse por trabajador habitual del centro de trabajo a efectos del cómputo del despido colectivo. La Directiva no ofrece precisión adicional alguna sobre cómo interpretar la habitualidad, siendo la jurisprudencia la encargada de su delimitación. Así, se han venido considerando como trabajadores habituales a todos los trabajadores que reúnan las notas de laboralidad, entendiéndose que se aplica tanto a los administradores de sociedade ${ }^{20}$ como los trabajadores temporales ${ }^{21}$, o incluso en un pronunciamiento más reciente a las trabajadoras embarazadas $^{22}$.

En suma, serán despidos colectivos las extinciones sustentadas en causas independientes de la persona o conducta del empleado y que, además, integre el elemento cuantitativo y temporal señalado por la normativa comunitaria. La regulación española se desajusta de la comunitaria, al referirse el Estatuto de los Trabajadores a esas extinciones asimilables y no a los despidos, como indica el TJUE. Por tanto, una vez más el Tribunal de Justicia nos aboca a reflexionar sobre la adecuada transposición y eficacia armonizadora de la Directiva realizada en nuestro país y a la necesidad de su modificación en una

16 STJUE de 13 de mayo de 2015, Rabal Cañas, asunto C-392/13. STJUE de 11 de noviembre de 2015, Pujante Rivera, asunto C-422/14.

17 GÓMEZ ABELLEIRA, F.J. y DÍAZ ZAFORAS, D., "La construcción judicial del concepto de despido colectivo por el tribunal de justicia de la unión europea”... ob. cit. 48.

18 Véanse, entre otras, STSJ Cataluña de 23 de abril de 1996 (Rec. 2604/96); Andalucía/ Sevilla de 27 de febrero de 2004 (Rec. 3826/03).

${ }^{19}$ STSJ Castilla León de 22 de septiembre de 2010 (Rec. 1147/2010).

${ }^{20}$ STJUE de 9 de julio de 2015, Balkaya, asunto C-229/14.

${ }^{21}$ STJUE de 11 de noviembre de 2015, Pujante Rivera, asunto C-422/14.

${ }^{22}$ STJUE de 22 de febrero de 2018, Porras Guisado, asunto C- 103/16. 
futura reforma legislativa que permitiese una armonización eficaz de la noción de despido colectivo.

\subsection{A nivel de umbrales de referencia}

Otro de los aspectos cuestionados en relación con el alcance o noción del despido colectivo, que contribuye nuevamente a reflejar las diferencias existentes en el derecho español y la normativa comunitaria, es el que refiere a la unidad de referencia espacial y temporal en el cómputo de los despido.

\subsubsection{Unidad de referencia espacial}

Siguiendo la regulación precedente, la Directiva 98/59/CE alude al centro de trabajo como el ámbito para el cómputo del número de extinciones, mientras que el artículo 51.1 ET emplea el término empresa y no el de centro de trabajo. El Tribunal Supremo ha venido justificando que el art. 51.1 ET haya optado por la empresa como unidad de cómputo, al considerar que es la que se trata de una mejora de garantía y protección de los trabajadores. Esta opción más favorable vendría además reforzada por la necesidad que impone nuestra normativa interna de que la empresa justifique la causa extintiva ${ }^{23}$.

A pesar de ello, se trata de una cuestión que ha sido objeto de relevantes pronunciamientos del TJUE que han obligado a modificar el criterio adoptado por el Tribunal Supremo español, al entender que la Directiva 98/59/CE se opone a una normativa nacional que introduce, como única unidad de referencia, la empresa y no el centro de trabajo, cuando la aplicación de dicho criterio obstaculiza el procedimiento de información y consulta ${ }^{24}$.

En tres sentencias coetáneas, USDAW, Lyttle y Rabal Cañas se ha planteado si la unidad de referencia que define la Directiva es la empresa en su conjunto o el centro de trabajo. El TJUE concluye que los conceptos de empresa y de centro de trabajo son distintos y éste, por regla general, es una parte de aquella; de modo que si las diversas unidades que integran la empresa pueden ser definidas como centro de trabajo, conforme a la Directiva, y a esa unidad se hayan adscritos los trabajadores afectados por el despido, es ésta la que debe entenderse como unidad de referencia a los efectos de determinar si los despidos efectuados pueden ser considerados despidos colectivos para poner en marcha el procedimiento

\footnotetext{
${ }^{23}$ SSTS de 18 de marzo de 2009 (Rec. 3672/2009) y 23 de enero de 2013 (Rec. 404/2013), entre otras.

${ }^{24}$ STJUE de 13 de mayo de 20015, Rabal Cañas, asunto C-392/13.
} 
de protección ${ }^{25}$. En otros términos, señala que la empresa como unidad de referencia sólo podría aceptarse si dicho elemento supone una protección adicional al mínimo recogido en la Directiva y no implica renuncia de la protección legal contenida en la misma; la sustitución del término "centro de trabajo" por el de "empresa" sólo puede considerarse favorable a los trabajadores si dicho elemento no implica abandono o reducción de la protección de los trabajadores.

No entra, en cambio, el Tribunal de Justicia en ninguna otra valoración sobre esos otros aspectos de la regulación que ofrece nuestra normativa interna. Se centra únicamente en el relativo a la unidad de cómputo, aunque sin ponerlo en relación con el ámbito que se deba utilizar de referencia para la apreciación de las causas económicas, técnicas, organizativas o de producción que exige el art. 51.1 ET, o para la puesta en marcha del procedimiento de información y consulta $^{26}$. Lo que viene a confirmar que esta unidad de referencia, el centro de trabajo, en los términos utilizados por la Directiva es el estándar mínimo que, en principio, sería indisponible por los Estados Miembros ${ }^{27}$.

En consecuencia, la jurisprudencia comunitaria obliga a realizar el cómputo en ambas unidades -empresa/centro de trabajo-; de forma tal que existe despido colectivo tanto en las situaciones en las que las extinciones de contratos computables superen los umbrales fijados en el art. 51.1 ET, tomando la totalidad de la empresa como unidad de referencia, como aquellas otras en las que se excedan esos mismos umbrales en los casos en que afecten a un único centro de trabajo aisladamente considerado, siempre que en el mismo presten servicios más de 20 trabajadores.

La doctrina académica ha justificado de forma dispar el desajuste entre el Derecho de la UE y el Derecho español en la determinación de la unidad de

${ }^{25}$ STJUE de 30 de abril de 2015, USDAW, asunto C- 80/14; STJUE de 13 de mayo de 20015, Rabal Cañas, asunto C-392/13 y STJUE de 13 de mayo de 2015 Lyttle, asunto C- 182/13 En el asunto USDAW y Wilson, aunque se produce una reducción de plantilla muy sustancial -más de 4000 trabajadores despedidos-, al computarse las extinciones centro por centro, y no a nivel de empresa, no se considera que se produzca un despido colectivo. En el caso Lyttle se trata de grandes empresas de distribución comercial, implantadas a nivel nacional y con miles de trabajadores repartidos en cientos de comercios o puntos de venta, muchos de los cuales tienen menos de 20 empleados. En el caso Rabal Cañas, en cambio, se trata de una empresa pequeña, que no llega a los 200 trabajadores, con solo dos centros de trabajo, uno en Madrid con 164 empleados y otro en Barcelona con 20.

${ }^{26}$ CASTRO ARGÜELLES, Ma A., Los conceptos de "centro de trabajo" y "despido colectivo» en el «Derecho de la Unión”, a propósito de la Directiva 98/59/CE... ob. cit. 9.

${ }^{27}$ SÁNCHEZ-URÁN AZAÑA, Y.; DE FUENTES GARCÍA-ROMERO TEJADA, C., "La trasposición de la Directiva 98/59/CE y el margen de apreciación de los derechos nacionales (I)", en Revista española de Derecho del Trabajo, 194 (2017) 120. 
referencia espacial en el cómputo de los despidos. Los razonamientos doctrinales son variados: desde que el legislador había optado por este criterio locativo, sobre la base del carácter de norma mínima de la Directiva y de la mejora a los trabajadores; quienes consideran que la unidad de referencia debe ser el centro de trabajo conforme indicaba la Directiva anterior, la 75/129/CE; o quienes consideran admisible la existencia de una interpretación mixta a favor de la inclusión en el periodo de referencia tanto a la empresa como al centro de trabajo $^{28}$, o que la dimensión global de la empresa debe continuar siendo la unidad preferente de cómputo ${ }^{29}$.

Desde esta perspectiva, la existencia de diferentes modelos nacionales hace evidente el desajuste en la definición de despido colectivo y, en concreto, en la unidad de referencia señalado en la Directiva comunitaria respecto de la legislación española ${ }^{30}$. Nuestra normativa laboral no contrapone la empresa y el centro de trabajo como unidades de referencia empresarial necesariamente diferenciadas, sino que, por el contrario, los asimila y equipara en todos esos aspectos tan esenciales y relevantes de las relaciones laborales, sin que resulten excluyentes el uno del otro ${ }^{31}$.

\subsubsection{Unidad de referencia temporal. Periodo de 90 días}

El último de los componentes en la definición es, de seguro, el que mayor arrastre de discrepancias acredita tanto a nivel nacional como frente a la normativa comunitaria. Nos referimos a cómo se determina el periodo de noventa días fijados para iniciar el cómputo de los despidos de cara a la consideración de las

${ }^{28}$ SÁCHEZ-URÁN AZAÑA, Y., y DE FUENTES GARCÍA-ROMERO TEJADA, C., "Despido colectivo y unidad de referencia (I), o.c., p. 134. CABEZA PEREIRO, J., "La última jurisprudencia del Tribunal de Justicia de la Unión Europea en torno a la Directiva de despidos colectivos: un problema de conceptos y de políticas legislativas", en Trabajo y derecho, 10 (2015) 83.

${ }^{29}$ MOLERO MARAÑON, M ${ }^{\mathrm{a}}$ L., "La ineludible reforma del despido colectivo en su ámbito de referencia", Documentación laboral, 111 (2017) 43.

${ }^{30}$ Un estudio exhaustivo y detallado sobre el alcance de la unidad de referencia de los despidos colectivos en el derecho comparado, véase en SÁNCHEZ-URÁN AZAÑA, Y., y DE FUENTES GARCÍA-ROMERO TEJADA, C., "Despido colectivo y unidad de referencia (I)..., o.c.

${ }^{31}$ STJUE de 30 de abril de 2015, USDAW, asunto C- 80/14; STJUE de 13 de mayo de 20015, Rabal Cañas, asunto C-392/13 y STJUE de 13 de mayo de 2015 Lyttle, asunto C- 182/13 En el asunto USDAW y Wilson, aunque se produce una reducción de plantilla muy sustancial -más de 4000 trabajadores despedidos-, al computarse las extinciones centro por centro, y no a nivel de empresa, no se considera que se produzca un despido colectivo. En el caso Lyttle se trata de grandes empresas de distribución comercial, implantadas a nivel nacional y con miles de trabajadores repartidos en cientos de comercios o puntos de venta, muchos de los cuales tienen menos de 20 empleados. En el caso Rabal Cañas, en cambio, se trata de una empresa pequeña, que no llega a los 200 trabajadores, con solo dos centros de trabajo, uno en Madrid con 164 empleados y otro en Barcelona con 20. 
extinciones como despidos colectivos. El último de los aspectos de la noción de despido colectivo que ha provocado una nueva intervención del TJUE es el relativo al cómputo temporal o periodo de tiempo durante el que deben realizarse las extinciones de los contratos a efectos del cómputo de despidos colectivos, es decir, cuándo empieza y terminar el periodo de cómputo de los 30 o 90 días.

El análisis de esta cuestión recomienda un sucinto repaso al marco normativo del Derecho comunitario y del derecho español.

Dentro del Derecho de la Unión, la Directiva 98/59/CE, concretamente en su art.1, otorga un derecho de opción en el periodo temporal de computo de los despidos bien de 30 o 90 días, a elección de los Estados miembros. En el primer caso -período de 30 días-, el número mínimo es al menos igual a 10 en los centros de trabajo que empleen habitualmente más de 20 y menos de 100 trabajadores, al menos el 10\% del número de los trabajadores en los centros de trabajo que empleen habitualmente como mínimo 100 y menos de 300 trabajadores, o al menos igual a 30 en los centros de trabajo que empleen habitualmente 300 trabajadores. En el segundo caso -período de 90 días-, el número mínimo es al menos igual a 20 , sea cual fuere el número de los trabajadores habitualmente empleados en los centros de trabajo afectados.

Por el contrario, el legislador español optó por una formulación híbrida, al utilizar un sistema mixto donde opta por el periodo de noventa días, pero con los umbrales fijados para el periodo de treinta días. Sin perjuicio de todo lo anterior, advierte también este precepto que "cuando en períodos sucesivos de noventa días y con el objeto de eludir las previsiones contenidas en este artículo, la empresa realice extinciones de contratos al amparo de lo dispuesto en el art. 52.c) en un número inferior a los umbrales señalados, y sin que concurran causas nuevas que justifiquen tal actuación, dichas nuevas extinciones se considerarán efectuadas en fraude de ley, y serán declaradas nulas y sin efecto".

En definitiva, el legislador español ha venido considerando que los dos métodos de cómputo del periodo de referencia, en el cálculo de los despidos colectivos, se refiere bien al período anterior a ese despido, o bien igualmente el período posterior al mismo, en caso de fraude, sobre la base argumental de que la Directiva no contempla límite temporal alguno a estos efectos.

No obstante, un último pronunciamiento del TJUE de 11 de noviembre 2020 Marclean Technologies, asunto en respuesta a la cuestión suscitada 
por el Juzgado de lo Social n. 3 de Barcelona ${ }^{32}$ cambia la percepción tenida hasta ahora y advierte que hay que tener en cuenta cualquier periodo de 30 o de 90 días consecutivos en el que haya tenido lugar ese despido individual y durante el cual se haya producido el mayor número de despidos, toda vez que el propio texto del art. 1, ap. 1, párrafo primero, letra a), de dicha Directiva no menciona, a efectos de calcular el número de despidos que se han producido, ningún límite temporal exclusivamente anterior o posterior al despido individual impugnado.

En consecuencia, el período de referencia previsto para determinar la existencia de un despido colectivo ha de calcularse computando todo período de treinta o de noventa días consecutivos anterior o posterior al despido y durante el cual se haya producido el mayor número de despidos efectuados por el empresario por uno o varios motivos no inherentes a la persona de los trabajadores, en el sentido de esa misma disposición. Como establece la normativa, el cómputo debe hacerse por períodos «sucesivos» de noventa días; por tanto, no cabe un cómputo variable. Debe fijarse un día concreto que será el día en el que se acuerda la extinción. Este día constituye el día final (dies ad quem) y el inicio del siguiente (dies a quo) ${ }^{33}$. Por tanto, a raíz de este último pronunciamiento del TJUE se plantea una nueva interpretación que considera que el período de referencia consiste en todo período de treinta o de noventa días en el que se haya producido el despido individual impugnado, sin distinguir en función de que dicho período sea anterior, posterior o en parte anterior y en parte posterior al despido individual.

La STJUE Marclean Technologies zanja así un enconado debate sobre si los 90 días a examinar eran los anteriores los posteriores al despido examinado ${ }^{34}$. Tras este pronunciamiento vale tanto lo uno cuanto lo otro, así como cualquier lapso de tiempo que esté a caballo de lo anterior y de lo posterior.

${ }^{32}$ El JS/3 de Barcelona, a través de un Auto fechado el 25 de marzo 2019.

${ }^{33}$ MONEREO PÉREZ, J.L., y ORTEGA LOZANO, P. G., "Despido colectivo y Derecho Social Comunitario: La reinterpretación en el método del cómputo del factor temporal de los despidos colectivos: criterio amplio a través del período continuo anterior/posterior". En $L a$ Ley Unión Europea, 89 (2021)17.

${ }^{34}$ Hasta esta sentencia la doctrina jurisprudencial (STS 11 de enero 2017, (Rec. 2270/2015) entendía que el último párrafo del art. 51.1 establece una norma general en virtud de la cual «el día del despido constituye el día final del plazo (el "dies ad quem") para las extinciones contractuales que se acuerden ese día y, al mismo tiempo, el día inicial (el "dies a quo") para el cómputo del período de los 90 días siguientes. En términos generales, 'el día en que se acuerda la extinción constituye el día final del cómputo del primer período de noventa días y el inicial del siguiente'» (criterio que se reitera en el ATS 27 de junio 2018, (Rec. 4599/2017); y, entre otras, también en la STSJ And $\backslash$ Sevilla 30 de enero 2020, (Rec. 3496/2018). 
A partir de esta sentencia se aplicará la denominada por la doctrina científica como "regla del compás", esto es, se tendrán en cuenta a efectos del cómputo de los despidos colectivos los producidos tanto antes como después a cualquier período de 30 o de 90 días (por consiguiente, sin quedar circunscrito a un período anterior ni posterior) ha te computarse un único periodo continuado de 90 días en el que se halle incluida la fecha del despido de referencia, pudiendo computarse tanto los días anteriores como los posteriores a dicha fecha.

En esta cuestión tan decisiva el TJUE ha desbaratado los criterios de nuestro Tribunal Supremo cuya sala de lo Social, reiteradamente, ha venido concluyendo que el periodo de 90 días debe determinarse hacia atrás, tomando como día de inicio del cómputo la fecha del despido individual objeto de impugnación por el trabajador despedido ("despido de referencia"). Como excepción a dicho criterio, el Tribunal Supremo sólo ha admitido el análisis de los 90 días siguientes a la fecha del despido de referencia, cuando la empresa había actuado fraudulentamente.

La jurisprudencia española en STS de 9 diciembre de 2020 aplicó parcialmente la jurisprudencia comunitaria mencionando en sus fundamentos jurídicos la existencia de esta sentencia del TJUE y de su doctrina interpretativa, en la que revisa el goteo de posibles ceses en los 90 días anteriores y posteriores a la fecha de despido de un trabajador para comprobar si se trata de un despido colectivo fraudulento, tal y como se estipula en n el artículo 51.1 del Estatuto de los Trabajadores $^{35}$. Con posterioridad a esta sentencia, la STS de 21 de julio de 2021 reconoce el cómputo móvil del cómputo de 90 días, bidireccionales, hacia atrás o hacia adelante del despido individual y donde centra el análisis en el requisito, no del periodo de tiempo, sino en su carácter discontinuo ${ }^{36}$. Quizá en un futuro no muy lejano tengamos un nuevo pronunciamiento sobre lo que deba entenderse por periodos consecutivos.

En cualquier caso, como también ha manifestado la doctrina científica, la proyección de esta doctrina sobre la calificación del despido no siempre resultará sencilla y pacífica ${ }^{37}$.

${ }^{35}$ STS de 9 de diciembre de 2020 (Rec. 55/2020).

${ }^{36}$ STS de 21 de julio de 2021 (Rec. 2128/2018). ROJO TORRECILLA, E., Despido colectivo. Computo de 90 días, sucesivos, hacia atrás o hacia adelante del despido individual. EL TS sigue la jurisprudencia del TJUE. Notas a la sentencia de 21 de julio de 2021:

http://www.eduardorojotorrecilla.es/2021/08/despido-colectivo-computo-de-90-dias.html.

37 SEMPERE NAVARRO, A.V., "Los umbrales del despido colectivo y el TJUE", en Actualidad Jurídica Aranzadi, 969 (2020). 


\section{UN APUNTE SOBRE EL DESPIDO COLECTIVO EN EL DERECHO COMPARADO}

La nueva configuración del despido colectivo propuesta por la jurisprudencia comunitaria, hace necesario aludir a su impacto no sólo en el derecho español, que también, sino en el derecho comparado.

Sin ánimo de exhaustividad, se analizará la normativa reguladora del despido colectivo en Alemania, Francia e Italia donde se observa que la configuración del mencionado tipo de despido presenta algunas discordancias de unos países a otros. Siguiendo la pauta armonizadora de la Directiva, el primer elemento a tener en cuenta en la definición del despido colectivo es la causa. En los países cuya regulación se ha analizado se contemplan las causas de despido, aunque de forma más genérica respecto de la norma española.

En Alemania como causas de despido se alude a "necesidades empresariales urgentes". Se trata de un concepto jurídico con apariencia de generalidad, aunque tiene un ámbito más restrictivo que la regulación española, porque alude a la "urgencia" en las necesidades empresariales. Se trata de un concepto jurídico indeterminado que habría que cuantificar. Aún así, no cabría en la normativa alemana una extinción cuando se produzcan cambios en el ámbito de los medios o instrumentos de producción, en los ámbitos de los sistemas o métodos de trabajo del personal, en el modo de organizar la producción o en la demanda de productos o servicios ${ }^{38}$. Las causas de despido colectivo en Italia también son muy genéricas, puesto que la norma sólo prevé que podrán llevarse a cabo extinciones contractuales como consecuencia de una reducción, transformación o cesación de la actividad ${ }^{39}$. En similares términos, en Francia la definición de la causa es considerablemente genérica, indicándose en el Código de Trabajo ${ }^{40}$ que las dificultades económicas o las mutaciones tecnológicas podrán justificar la extinción de contratos.

En lo que refiere a los umbrales legales, presentan más similitudes que diferencias. En Alemania se exige para poder despedir colectivamente que afecte en un periodo de 30 días a 5 trabajadores en empresas que empleen a más de 20 y menos de 60 trabajadores; $10 \%$ de los trabajadores en empresas

38 YSÀS MOLINERO, H., “Aproximación al despido colectivo en Europa: una breve comparación de los casos español, francés, alemán e italiano" Anuario IET, vol. 1 (2013) 68.

${ }^{39}$ Artículo 24 de la Legge 223/1991, de 23 de julio. Norme in materia di cassa integrazione, mobilità, trattamenti di disoccupazione, attuazione di direttive della Comunità europea, avviamento al lavoro ed altri disposizioni in materia di mercato del lavoro.

${ }^{40}$ Arts. L-1233 y siguientes del Code du Travail. 
que empleen a más de 60 y menos de 500 trabajadores y 30 trabajadores en empresas que empleen a más de 500 trabajadores. En Italia la extinción que afecte en un período de 120 días como mínimo y siempre que se despida a 5 trabajadores en empresas que empleen a más de 15 trabajadores. Los despidos deberán afectar a la misma unidad productiva o a las unidades productivas situadas en una misma provincia. Debe destacarse, además, que la normativa sobre despidos colectivos no se aplicará a las empresas que cuenten con una plantilla de menos de 15 trabajadores. En Francia, será despido colectivo cuando la extinción afecte en un período de 30 días, al menos, a 10 trabajadores.

\section{SOBRE LA EFICACIA ARMONIZADORA DE LA DIRECTIVA 98/59/CE}

La complejidad del concepto de despido comunitario en la Directiva y la heterogénea transposición realizada por los Estados miembros ha provocado que el TJUE haya tenido que reinterpretar la mayor parte de los elementos configuradores de la noción legal de despido colectivo; además ha dejado al descubierto desajustes en la transposición de la Directiva comunitaria.

El mencionado proceso de revisión conceptual abordado por el TJUE contiene luces y sombras que están poniendo a prueba la viabilidad y eficacia de la noción de despido colectivo en el derecho nacional y en el derecho de la Unión.

No hay duda en que el TJUE viene aportando luz a la compleja noción del despido colectivo, incorporando innovadoras soluciones pro-operario en la protección de los trabajadores frente a los despidos económicos. Sin embargo, como contrapunto, no pueden ignorarse algunas sombras, concentradas en la incertidumbre e inseguridad jurídica que está generando para las empresas, unas veces imputables al propio Tribunal europeo con pronunciamientos excesivamente inconcretos y/o ambivalentes, otras a los jueces españoles, aferrados en algunos casos, a interpretaciones forzadas más allá de una mera interpretación correctora ${ }^{41}$.

Especialmente relevantes son las sombras que plantea la última sentencia del TJUE en la interpretación de la unidad de referencia temporal de los despidos colectivos y el relevante impacto que ha tenido y va a tener en la jurisprudencia española que supone un paso más en la necesidad de reconfigurar el despido colectivo en fraude de ley, ya que con este último pronunciamiento del Tribunal de Justicia, resulta irrelevante la intención empresarial y solo se precisa que

\footnotetext{
${ }^{41}$ SEMPERE NAVARRO, A.V., "Los umbrales del despido colectivo y el TJUE”, o.c.
} 
concurra el número suficiente de despidos en un periodo de 90 días consecutivos, antes o después del despido individual, o una revisión de la interpretación del plazo de caducidad del que dispondrá una persona trabajadora que ha visto extinguido su contrato de trabajo, tras descubrir que el número de extinciones posteriores a su despido es suficiente para considerarlo parte de un despido colectivo encubierto ${ }^{42}$.

Algunos de estos desajustes podrán suplirse mediante una nueva interpretación del derecho interno de la forma más favorable para la vigencia y observancia total de la normativa comunitaria; sin embargo, en otros casos requerirán, sin ninguna otra alternativa, de modificaciones legislativas que entrañan decisiones de política legislativa de más difícil calado ${ }^{43}$. Como ya se venía señalando, el papel de Tribunal de Justicia como impulsor, involuntario en muchos casos, de cambios y reformas en las legislaciones laborales nacionales se consolida sin duda alguna ${ }^{44}$.

Llegados a este punto, conviene centrarse no en las principales aportaciones de la oleada de pronunciamientos del TJUE sino en reflexionar sobre si resulta necesaria la reformulación del concepto de despido colectivo para integrar las nuevas interpretaciones jurisprudenciales en relación con las causas o motivos de despido, la unidad de referencia espacial en el cómputo de los despidos y, ahora también, el momento temporal en el que deben computarse los 90 días para cuantificar los despidos. Para constatar la necesaria reforma de la noción legal de despido bastaría con señalar que la corrección de la norma por parte de la doctrina jurisprudencial se constituye un motivo sólido y razonable que propicia la necesidad de una reforma normativa por resultar controvertida su aplicación en su redacción actual.

En el escenario de grave crisis económica vivida a raíz de la Covid19 en el que las empresas necesitan unos mecanismos legales claros y de fácil aplicación para reestructurar sus plantillas de empleados, parece que la justicia tanto a

${ }^{42}$ Véase, MANEIRO VÁZQUEZ, Y., "Los 90 días determinantes del despido colectivo: certus an, ¿certus quando? Comentario a la Sentencia del Tribunal de Justicia de la Unión Europea de 11 de noviembre de 2020, asunto C-300/19", en Revista de Trabajo y Seguridad Social. $C E F, 454$ (2021) 142. SALA FRANCO, T., "Balance jurisprudencial acerca del concepto legal de despido colectivo y del cómputo de las extinciones contractuales producidas en un periodo de 90 días", o.c.

${ }^{43}$ CABEZA PEREIRO, J., "La última jurisprudencia del Tribunal de Justicia de la Unión Europea en torno a la Directiva de despidos colectivos: un problema de conceptos y de políticas legislativas", o.c.

${ }^{44}$ MIRANDA BOTO, J.M., "El impacto de la jurisprudencia reciente del Tribunal de Justicia en la legislación laboral española: los ajustes incumplidos”, en Aranzadi Unión Europea, 5 (2018). BIB $2018 \backslash 8759$ 
nivel europeo como nacional, introduce criterios que comportan complejidades añadidas a los ya difíciles procesos de amortización de puestos de trabajo.

Nuestro marco actual responde, en esencia, a un modelo fijado por la doctrina judicial, y a pesar de ello no se han resuelto todas las incertidumbres que planteaba dicha regulación.

Hemos pasado de un modelo donde los despidos colectivos no generaban mucha litigiosidad, a un modelo basado en la confrontación judicial. Por otra parte, en aras a la diferente transposición de las directivas comunitarias en los Estados miembros y ante el considerable número de cuestiones prejudiciales que se han presentado al respecto, quizá también sería adecuado plantearse, de lege ferenda una posible modificación de la Directiva comunitaria con el objetivo de revisar su eficacia armonizadora en el ámbito de los despidos colectivos.

Desde el punto de vista cuantitativo, atendiendo el legislador a los umbrales que fija la Directiva, debe recordarse que no hay una pauta común entre los países de la UE que han optado en sus legislaciones por incluir el centro de trabajo como unidad de referencia, lo que impide al legislador español pensar en una solución que se adecue a la regla de otros ordenamientos jurídicos ${ }^{45}$.

El legislador español optó por una transposición de la Directiva concreta a nivel causal e híbrida en su formulación, al utilizar un sistema mixto donde opta por el periodo de noventa días, pero con los umbrales fijados para el periodo de treinta días. Por todo ello, como ha señalado la doctrina la reforma del art 51 del ET es de "imperiosa necesidad"46, aunque a la luz de la jurisprudencial emanada del TJUE la delimitación del despido colectivo resulte ser una cuestión realmente compleja. La duda sería si el cambio se produce aprovechando la anunciada reforma del Estatuto de los trabajadores o a nivel supranacional valorando también una posible modificación de la Directiva que incorpore los criterios del TJUE, en aras a dotar de eficacia y eficiencia en la armonización de leyes como objetivo prioritario de la Unión Europea.

${ }^{45}$ POQUET CATALA, R., "La última doctrina en torno al criterio cuantitativo y temporal del despido colectivo, ¿fin del debate? en VV.AA., Reestructuraciones empresariales, Comunicaciones del XXXI Congreso Anual de la asociación española de Derecho del Trabajo y de la Seguridad Social, Ministerio de trabajo y economía social, Madrid 2021, p. 541.

${ }^{46}$ MANEIRO VÁZQUEZ, Y., "Los 90 días determinantes del despido colectivo: certus an, ¿certus quando? Comentario a la Sentencia del Tribunal de Justicia de la Unión Europea... ob.cit.144. PÉREZ DEL PRADO, D., El Tribunal de Justicia y el despido colectivo español: una relación compleja, en VV.AA., Reestructuraciones empresariales, Comunicaciones del XXXI Congreso Anual de la asociación española de Derecho del Trabajo y de la Seguridad Social, Ministerio de trabajo y economía social, Madrid 2021, p. 526. 
Teniendo en cuenta el esfuerzo que tanto jueces nacionales como el TJUE realizan en la labor de interpretación y adecuación entre el derecho nacional y el de la Unión, -cuyo ejemplo más evidente se sitúa en el despido colectivo, pero que también es visible en otras materias-, quizá sería una buena oportunidad para reflexionar si el propósito armonizador de la Directiva comunitaria se logra o, por el contrario, sigue siendo una tarea pendiente que propicia un nuevo replanteamiento.

\section{BIBLIOGRAFÍA}

- CABEZA PEREIRO, J., "La última jurisprudencia del Tribunal de Justicia de la Unión Europea en torno a la Directiva de despidos colectivos: un problema de conceptos y de políticas legislativas", Trabajo y derecho 10 (2015).

- CASTRO ARGÜELLES, Ma A., "Los conceptos de «centro de trabajo» y «despido colectivo» en el «Derecho de la Unión», a propósito de la Directiva 98/59/CE”, en La Ley Unión Europea, 29 (2015).

- DESDENTADO BONETE, A., "La delimitación legal del despido colectivo. El despido colectivo de hecho", en VV.AA., Tratado de despido colectivo, Dir. Martín Godino Reyes, 2016.

- GÁRATE CASTRO, J., "Régimen jurídico del despido colectivo", en Revista, Dereito Vol. 22, nº extraordinario, (2013).

- GARCÍA PERROTE ESCARTÍN, I., "La aplicación por el Tribunal de Justicia de la Unión Europea de la Directiva sobre despidos colectivos y su repercusión en el derecho español", en Actualidad Jurídica Uría Menéndez, 49 (2018).

- GÓMEZ ABELLEIRA, F.J., y DÍAZ ZAFORAS, D., "La construcción judicial del concepto de despido colectivo por el tribunal de justicia de la unión europea", en Revista Española de Derecho Europeo, 57 (2016).

- MANEIRO VÁZQUEZ, Y., "Los 90 días determinantes del despido colectivo: certus an, ¿certus quando? Comentario a la Sentencia del Tribunal de Justicia de la Unión Europea de 11 de noviembre de 2020, asunto C-300/19", en Revista de Trabajo y Seguridad Social. CEF, 454 (2021).

- MIÑARRO YANINI, M., "La causa del despido colectivo en el Convenio n. ${ }^{\circ}$ 158 de la OIT y en la Directiva 98/59/CE”, en Actualidad laboral, 8 (2011). 
- MIRANDA BOTO, J.M., "El impacto de la jurisprudencia reciente del Tribunal de Justicia en la legislación laboral española: los ajustes incumplidos", en Aranzadi Unión Europea, 5 (2018). BIB 2018\8759.

- MOLERO MARAÑON, M L., "La ineludible reforma del despido colectivo en su ámbito de referencia", Documentación laboral, 111 (2017).

- MONEREO PÉREZ, J.L., "El despido colectivo en la jurisprudencia de Tribunal de Justicia de la Unión Europea y su incidencia en el Derecho interno", en Temas Laborales, 130 (2015).

- MONEREO PÉREZ, J.L., y ORTEGA LOZANO, P. G., "Despido colectivo y Derecho Social Comunitario: La reinterpretación en el método del cómputo del factor temporal de los despidos colectivos: criterio amplio a través del período continuo anterior/posterior”, en La Ley Unión Europea, 89 (2021).

- PÉREZ DEL PRADO, D., El Tribunal de Justicia y el despido colectivo español: una relación compleja, en VV.AA., Reestructuraciones empresariales, Comunicaciones del XXXI Congreso Anual de la asociación española de Derecho del Trabajo y de la Seguridad Social, Ministerio de trabajo y economía social, Madrid 2021.

- POQUET CATALA, R., "La última doctrina en torno al criterio cuantitativo y temporal del despido colectivo, ¿fin del debate?, en VV.AA., Reestructuraciones empresariales, Comunicaciones del XXXI Congreso Anual de la asociación española de Derecho del Trabajo y de la Seguridad Social, Ministerio de trabajo y economía social, Madrid 2021.

- ROJO TORRECILLA, E., Despido colectivo. Computo de 90 días, sucesivos, hacia atrás o hacia adelante del despido individual. EL TS sigue la jurisprudencia del TJUE. Notas a la sentencia de 21 de julio de 2021:

http://www.eduardorojotorrecilla.es/2021/08/despido-colectivo-computo-de90-dias.html.

- SALA FRANCO, T., "Balance jurisprudencial acerca del concepto legal de despido colectivo y del cómputo de las extinciones contractuales producidas en un periodo de 90 días", en Revista de Trabajo y Seguridad Social. CEF, 455 (2021).

- SÁNCHEZ-URÁN AZAÑA, Y., y DE FUENTES GARCÍA-ROMERO TEJADA, C., "La trasposición de la Directiva 98/59/CE y el margen de apreciación de los derechos nacionales (I)", en Revista española de Derecho del Trabajo, 194 (2017). 
- SEMPERE NAVARRO, A.V., "Los umbrales del despido colectivo y el TJUE”, en Actualidad Jurídica Aranzadi, 969 (2020).

- YSÀS MOLINERO, H., "Aproximación al despido colectivo en Europa: una breve comparación de los casos español, francés, alemán e italiano", en Anuario IET, vol. 1 (2013). 